ton. He was licensed in 1893 , but our records fail to show that he is a graduate of any medical college.

It seems that the Williams concern, in common with most mail-order medical concerns, disposes of its "sucker lists" after these have ceased to be profitable. A company in New York City which made a business of purchasing for subsequent rental or resale original letters written to medical mail-order conccrus, listed under its "Kidney Letters" the following:

$62,366 \ldots$.... DR. D. A. Williays, 1901 to 1906

$29,076 \ldots$. Dr. D. A. Williams, Late 1906 to 1910.

$8,655 \ldots .$. Dr. D. A. Wililams, Late 1900 to 1909.

In accordance with the tenets of empiricism, the public, which is asked to pour this nostrum down its throat, is given no hint as to what there is in it. But:

"The Williams Tratment is different from" any Kidney or Bladder remedy on the market. Its ingredients are scientifically blended and of a distinctly curative nature. It does more than merely deaden pain and give short relicf. It is pure and wholesome and does not contain Alcohol, Morplin, Opium, Cocain, Saltpeter or Dangerous Drugs.

"It expels Cric Acid, belps to sterilize the urine, cleanses the kidneys and gives tone and strength to their tubular cells. It is a restorative of Kiduey Vitality and casts out poisonous matter whether of a toxic nature or not. It cleanses the bladder and quells inflammation of its mucous surface and its effect on calculus or gravel formation is to aid in their dissolution. It is unequalled in building up weak urinary ducts and glands and a great aid to natural passage of urine."

The Dr. D. A. Williams Company sends, to those who write for it, a free sample, emphasizing that this is but a trial and that the recipicut should purchase at least a full-sized bottle, $\$ 1.25$ - 6 bottles for $\$ 6.00 . "$ A letter, printed to simulate an individual trpewritten communication, is also sent, explaining that "Dr. Williams lias treated uric acid conditions for more than thirty-six ycars and he varies the treatment to meet the demands for cach different condition." For this reason the prospective purchaser is urged to fill out the symptom blank so that advice "concerning diet and other matters" may be sent.

Several bottles of the Williams Treatment were purchased and submitted to the A. M. A. Chemical Laboratory for examination. Here is what the chemists report:

\section{CHFMISTS RFPORT}

"The Williams Treatment is a dark reddish brown mixture with the odor of wintergrcen or methyl salicylate. It contains considerable undissolved crystals which pass into solution when water is added to the 'treatment.' Acetate. bicarbonate, caramcl, potassium, traces of formate and of salicylate were found prescnt. No nitrogenous drugs or alkaloids could be detcetcr. Potassium was the only metal found. Samples vary somewhat in the gliantities of the coustituents found but are approximately as follows:

"Residue when dried at 100 (". (including undissolved crystals) 57 gm. in 100 c.c.

"Potassium acctate (calculated from total volatile acids) $48 \mathrm{gm}$, in 100 c.c.

"Potassium hicarbonate $7 \mathrm{gme,}$ in 100 c.c.

"The formate found was in very small amounts and may have been formed from the caramel color during the distillation with acid. The salicrlate. also in very small amount, no doubt came from the methyl salicylate or oil of wintergreen.

"From this examination we conclude that Williams Treatment is essentially a mixture containing, in 100 c.c. $48 \mathrm{gm}$. potassium acetate in solution and about $7 \mathrm{gm}$. potassium bicarbonate, the latter heing largely undissolved. The mixture is colored with caramcl and flavored with oil of wintergreen or methyl salicylate."

A study of "patent medicines" makes it possible to deduce with a fair clegree of accuracy the probable composition of these products. Nostrums of the "headache cure" type, for example, may be counted on to contain acetanilid. phenacetin or antipyrin; the "tonics" and "female weakness cures" invariably have for their most active drug, alcohol; the epilepsy "cures" contain, of course, bromids. Remedics for the selftreatment of discases of the kidneys-and also for diabetes, for the nostrum maker fosters the common fallacy that diabetes is a "kidney disease"-practically always contain as their most active ingredient a diuretic. The "Williams Treatment" runs truc to type. For all practical purposes, the "treatment" may be said to be a simple solution of potassium acetate, colored and flavored. From a public health standpoint, there are several objections to the Williams Treatment : first, kidney disease is much too serious a condition to be self-treated; second, attempts to diagnose and treat ailments on the mail-order plan are the sheerest quackery; third, the Williams nostrum is secret in composition; and, fourth, analysis shows the preparation contains a renal irritant which may seriously damage a kidney whose structure is already in a state of acute or chronic inflammation.

\section{Correspondence}

\section{THE GOLDENROD AND "HAY-FEVER"}

To the Editor:-I have been very much interested in an editorial comment in a recent number of THE JoURNAL (April 19, 1919), in which it is claimed that hereafter the goldenrod must be cast out of the company of the flowering plants which are generally supposed to cause the onset of the disease falsely known as hay-fever. Whenever I have chanced, in writing or debate, to discuss the alleged specific influence of pollen as the solitary source of that affection or to combat the well-nigh universal popular belief that this particular wild flower is, among others, responsible for its manifestations, in endeavoring to plead its innocence of the charge, I have always turned involuntarily to the descriptive verse of Lowell, in which he paints, with exquisite delicacy, the national flower:

\section{Dear common flower that growest beside the way,} Fringing the dusty road with harmless gold.

The object of this brief note is not to open or disturb the pollen question, but in avoiding it and leaving it, simply to say in passing that one by one some of the best known and most conspicuous of the natural objects which by common consent have been regarded as unquestioned causes of the malady and inseparably connected with the mechanism of its attacks have been shown by recent experiment to be pathologically sinless and innocuous. Yesterday it was the rose; today it is the roadside's guiltless gold; tomorrow it will be some other equally "well known" pollen-laden carrier of infection.

The term "hay-fever" is a singularly unfortunate misnomer. Its origin is obscure. It seems to have come into general use in the first quarter of the last century (somewhere between the vears 1819 and 1828 ), probably through some irresponsible, unscientific, popular medium, and at once became the commonly accepted name for the affection. Had his contemporaries listened to Bostock, who repudiated the employment of the term, we would before this have traveled much farther on the road to the solution of the nature of a condition which is not a fever and which is not caused by hay.

In the exclusive search for its explanation in the flowery kingdom of plants, we are in grave danger of literally going very far afield, of losing sight of the complex forces concerned in its production which are inherent in the person limself, and by diverting the mind from more essential etjologic conditions and by introducing an element of confusion into the investigation of the complaint, we may in a large measure retard the progress of therapeutic inquiry. Indeed, in the light of the passing conception of its pathology, which at present has possession of the hour, the treatment is inadequate, uncertain and unsatisfactory, and is carried out often with much trouble, with considerable discomfort and personal inconvenience and in some instances with dangerous results.

The true character of this remarkable disorder is still elusive, baffling and far off. Through the uncertain and changing atmosphere which surrounds it we as yet see dimly. The solution of the problem must be approached not hastily by one avenue alone, but along many paths of patient search. Let us broaden, not contract, the horizon of our observation. Among other things, let us look beyond the 
narrow study of one or more exciting causes into the nervous power that makes their operation possible, and, by viewing it from every angle and from a higher vantage ground, let us hope to hasten the coming of the day when the whole subject shall be lifted out of the dust of controversy and out of the darkness of hypothesis into the light of imperishable fact.

John N. Mackenzie, Baltimore.

\section{THE ADMINISTRATION OF ARSPHENAMIN}

To the Editor:-In your issue of May 10 you publish a letter from the director of the Hygienic Laboratory, U. S. Public Health Service, in which he declares it as a requisite to safe administration of arsphenamin that $0.1 \mathrm{gm}$. of the drug should be dissolved in at least 30 c.c. of fluid and that each injection of $0.3 \mathrm{gm}$. of the drug should require at least six minutes.

While I recognize that it is a wise policy to be overcareful in the administration of such a powerful drug and to err, if at all, on the safe side, I must take issue with the concluding remarks: "any physician who fails to observe these precautions should be considered as directly responsible for serious results that follow the improper use of the drug." As a matter of fact, I can state that in the many thousand injections which have been given in my service at Mount Sinai Hospital, it has been the standard rule to dissolve each $0.1 \mathrm{gm}$. in $20 \mathrm{c.c}$. of freshly distilled water, and to inject it, not with undue haste, but only in exceptional cases where small veins require the use of small needles, as slowly as Dr. McCoy suggests. The average injection takes about half the time defined by him as the minimum.

It is not in the spirit of controversy but with the aim of protecting the medical profession that I ask you to publish this letter, for I realize that if the occurrence of unavoidable reactions, rare as they are, should lead to a suit for malpractice, a well meant but too apodictical statement from such an authoritative source might be detrimental to a member of the profession. H. Goldenberg, M.D., New York.

\section{REPRINTS ON DISORDERS OF THE BLOOD}

To the Editor:-I am setting out to make a collection of reprints and cuttings from the medical press of papers dealing with the clinical and experimental aspects of disorders of the blood. I have already about 2,000 . These are indexed and filed and will, I hope, prove of permanent value.

American literature is not so well represented as I could desire. I have most of the papers on Gaucher's splenomegaly and excerpts from your own pages for the last few years, but much is still lacking. Would you be so good as to print this letter and allow me to ask those interested in the subject to send me any reprints they have.

Accounts of disease chacterized by abnormal shapes of the red cells and by abnormal phagocytosis are practically confined to American literature; there also one looks for much of the work on the spleen and nearly all that on hemolymph glands; purpura is much more fully dealt with than in English literature, and, generally speaking, we have little to compare with your experimental work.

It would be impossible for me to write to each author individually or to keep track of every paper published. Nor can I subscribe to all the journals in which this work is found.

If any reprints of my own are of sufficient interest, I shall of course be delighted to exchange them. Any reprints sent will be acknowledged at once.

I thank you in advance for your courtesy.

GoRDON WARD, M.D.

The Vine, Sevenoaks, Kent, England.

\footnotetext{
A Foresight.-I hope to live to see the time when the increased efficiency in the public health service-federal, state and municipal-will show itself in a greatly reduced death rate. The federal government can give a powerful impulse to this end by creating a model public health service, and making our national capital a model, sanitary city._-President Taft.
}

\section{Queries and Minor Notes}

Anonymous Communications and queries on postal cards will not be noticed. Every letter must contain the writer's name and address, but these will be omitted, on request.

\section{GLUTEN FLOUR FOR DIABETES}

To the Editor:-Will you give me the address of a company which makes gluten flours to be used in the treatment of diabetic patients? Do you consider gluten flour reliable in the treatment of diabetes?

$$
\text { C. T. PANKhurst, M.D., North Star, Mich. }
$$

ANswer.-Gluten flour is not a "treatment" for diabetes in the sense that it has any remedial value. The treatment of diabetes is essentially dietetic and hygienic, drugs playing a minor rôle. An important feature of the dietetic treatment is the restriction of the carbohydrate intake. As the commonest of the carbohydrate-containing foods is bread, the problem of substituting for ordinary bread a product somewhat similar in character, but without so high a starch content, becomes important. Gluten flours have been developed for this purpose. They are essentially wheat flours from which a large proportion of the starch has been removed, leaving a proportionate excess of the protein element (gluten). It thus becomes obvious that the important element in gluten flours is not the presence of larger amounts of protein, but the comparative absence of starch. There are many so-called gluten flours on the market which are extremely dangerous for use in diabetes because of the large proportion of starch they contain. A safe gluten flour is marketed by Herman Barker, Sommerville, Mass. This has been accepted by the Council on Pharmacy and Chemistry for inclusion in New and Nonofficial Remedies. The Barker product comes in three grades: Grade A contains 4 per cent. carbohydrate; Grade B, 7 per cent.; Grade C, 12 per cent. Certain flours for the use of diabetics in making breads, muffins, etc., that are low in carbohydrate content have also been admitted to N. N. R. These, however, do not have wheat flour as their base, and are therefore not gluten flours, the protein element being derived from the soy bean in one case and from milk casein in another.

\section{ABSORPTION OF WATER FROM THE STOMACH}

To the Editor:-I have been taught that water is not absorbed from the stomach. Dr. Casares (The Journal, May 3, 1919, p. 1336) speaks repeatedly to the contrary. Both cannot be right. Is there anything new concerning this question, pro or con?

Evgar A. Hall, M.D., Coal City, Ill.

ANSwER.-The article referred to is on the "Treatment of Malaria" by J. M. Casares y Bescanza, published in plus Ultra, Madrid, p. 186, and abstracted in THE Journal of May 3. According to most physiologic textbooks, water is not absorbed from the stomach. Fluids pass through the stomach rapidly and are absorbed from the intestine. For years physiologic laboratories have given to medical classes a practical demonstration of this fact. A cat is lightly anes. thetized, and 50 c.c. of distilled water heated to $37 \mathrm{C}$. is introduced into the empty stomach, the cardiac orifice of the stomach having previously been ligated off and a ligature placed about the pylorus. A similar amount of water is introduced into the small intestine, both ends of which are closed by ligatures. Care is taken not to interfere with the blood supply to the stomach or intestine. The animal is allowed to recover from the anesthetic and after from three to four hours is again anesthetized. The gastric and intestinal contents are measured, and the stomach is found to contain, on the average, about 47 c.c. of the water introduced - sometimes more, sometimes less; the intestines are invariably empty. Hence, the stomach absorbs practically none of the water, while the intestines absorb all. The slight apparent absorption from the stomach-3 c.c. in three hours - may be accounted for by the adherence of some of the water to the mucous membrane, and this water cannot be recovered. Experiments have shown that absorption of pure distilled water from the stomach is practically nil.

Saline solutions, however, are absorbed from the stomach in appreciable degree when in comparatively high concentration. Howell writes of sodium iodid solution that "Not until its solutions reach a concentration of 3 per cent. or more does its absorption become important." Experiments have shown that solutions of strychnin are absorbed from a Pawlow's stomach of a dog, precluding the possibility that the solutions were passed into the intestine before absorp- 